\title{
Disaster, Infrastructure Damage, and Health
}

\author{
Valeria Scapini
}

Centro de Investigación en Innovación, Desarrollo Económico y Políticas Sociales (CIDEP), Universidad de Valparaíso, Pasaje la Paz 1301, Viña del Mar, Chile

Corresponding Author Email: valeria.scapini@uv.cl

https://doi.org/10.18280/ijsse.100208

Received: 3 June 2019

Accepted: 8 July 2019

\section{Keywords:}

natural disasters, earthquake, health, healthiness, public policy, damaged houses, diseases, probabilistic models, difference in difference in differences estimator

\begin{abstract}
Natural disasters generate great economic costs, such as loss of human lives, damage to people's health and the loss of goods and infrastructure. In this sense, the case of Chile is particularly interesting, as it is located in the 'Pacific Ring of Fire' and is considered one of the most seismically active countries in the world. Based on the evidence from the 2010 earthquake, an empirical study was carried out using the panel survey 'CASEN Post earthquake 2010' and the panel of mandatory denotification diseases provided by the Ministry of Health between 2008 and 2013. Four models of difference in difference were estimated: The first to determine the effect of the disaster on the number of foodborne diseases, the second evaluates if the incidence of diseases is greater in areas closer to the epicenter, the third if the damage of the home correlates with the incidence of diseases and finally, the fourth is in charge of dealing with possible problems of endogeneity. The results include the causal relationship between the occurrence of the earthquake and the incidence of salmonella, as well as the correlation between housing damage and the incidence of paratyphoid fever, hepatitis A and salmonella. The main focus of the present study was to investigate potential outbreaks of foodborne diseases and generate evidence for the implementation of health public policies.
\end{abstract}

\section{INTRODUCTION}

Natural disasters happen in every continent of the world and its frequency has arisen in recent years. Natural disasters affect people directly or indirectly and generate a series of consequences which may cause health damage, the loss of properties, goods, and human lives. Due to the inevitability of natural disaster occurrences, it is necessary to develop professional researches which will design and implement public policies in order to work on prevention, solution, and reconstruction $[1,2]$.

Earthquakes happen in the areas of the ground surface where limits the tectonic plates. When tectonic plates move, they deform the rocks of the plate on both sides, also releases the energy in the form of heat and shock waves which cause earthquakes. When the vibration reaches the earth's surface, infrastructure will be damaged which may also get people injured or killed [3, 4]. Speaking of earthquakes, according to The World Organization of Volcano Observatories (WOVO) [5, 6], Chile is considered as one of those countries in the world that are more earthquake-active because Chile is located in a region which is known as 'Pacific Fire Belt' where limit tectonic plates are in permanent friction and has the most dormant volcanoes. Therefore, Chile is well-known in the topic of disaster management worldwide.

The earthquake in 2010, February 27th stood out from all the disasters that happened before since it reached magnitude 8.8 of the Richter scale. The epicenter was eight kilometers from the west of Curanipe, 115 kilometers from nor-northeast of Concepcion. The earth- quake started at 03:34 am and it lasted approximately 3 minutes. From Santiago to Temuco, a distance of almost 700 kilometers where lives 80 percent of the population of Chile, were all affected. There were 507 fatal victims and near 444.000 damaged houses. Thus, the care priority was water supply, food, and basic services such as health, transportation, and communication [7]. Also, the search for missing people was crucially important as well. Moreover, it is estimated that $30 \%$ to $40 \%$ of victims will have psychological problems afterward the earthquake and onethird of them will be suffering around ten years. Because of this, the affected areas should have psychological support too [8].

Damage of houses and household health infrastructure, lack of drinking water, and poor hygiene condition are considered as important reasons for morbidity and mortality. This study aims to research how earthquake influences the increase of foodborne illness (ETA). In this paper, it points out that in the world $[9,10]$, near 1.8 millions of annual deaths are generated by diarrheal diseases which constitute $19 \%$ of mortality among children and elderly people [11]. Moreover, diarrheal disease is an important factor that may cause mobility and mortality of elderly people [12]. With that, it also impedes economic development. Among ETA, the most common one is salmonellosis, which is caused by salmonellosis bacteria. It affects dozens of millions of people annually in the world and leads to more than ten thou- sand deaths per year $[9,10]$. Only in 2018, it has been registered for more than 100.000 cases of UE of salmonella including Salmonella typhi [13].

This study tries to find the answer to these questions: Is there a relationship between the occurrence of an earthquake and the incidence of foodborne diseases? Are damages of environment related to foodborne disease? This research is 
divided into the following parts. The second session is a literature review, the third and the fourth sessions demonstrate the data and the methodology that is used. Session 5 presents empirical results and a set of sturdiness test and at the end, session 6 is the conclusion of the research.

\section{LITERATURE REVIEW}

There is a classification of disasters that is based on their origin and their types. This classification possesses a high degree of consensus in the world which is divided into two main groups: natural disasters and disasters caused by mankind [14-16]. Particularly, [17] natural disasters are referred to those extreme events that are caused by geophysical factors and affect an exposed and vulnerable society in such a way that beyond the capacity of the society. Hence, extra assistance is needed.

Work of the United Nations such as the International Decade for the Reduction of Natural Disasters has allowed increasing attention towards diverse threats with which human being coexists [18]. Likewise, international development policies have focused on the protection of vulnerable people before the avoidable loss, regarding natural disaster as an exceptional fact that is not part of the development theory [19]. However, the world, which is mediated by technology and the fundamental role of social networks in our life, has increased the investigation in the natural science field in order to improve the ability to predict such disasters and dealing with them. Nevertheless, economic research related to them has not advanced in the same way [20].

Among the studies that estimate social and economic costs, the World Bank [21] points out that the social and economic cost of natural disasters has increased in recent years as a result of the growth of population. It points out that among social and economic costs, there are the loss of lives, destruction of infrastructure and poverty. The last is due to the diversion of resources whose objective is to overcome poverty towards plans for reconstruction and recovery of damaged areas, which causes delays in the first one. In this sense, you can say that these natural disasters cause enormous economic loss in the world. However, the caused damage is related to the income level of a country. The economic losses are higher in developed countries [22], but the proportion of GDP is lower [23].

The researches, which try to identify the determinants of the direct costs of disasters, most of them propose a model that explains the direct damages by using primary initial damages measures such as mortality, morbidity or loss of capital, and among all the considered independent variables, the magnitude of the disaster and the vulnerability of the country to disasters are included. The sensitivity of a country on the impact of natural disasters can increase according to the level of economic development. Kahneman and Krueger [24] conclude that in those richer countries generate fewer deaths from natural disasters which have the same severity.

Among all the researches that study disasters, infrastructure and consumption behavior, it is worth highlighting the one made by Acconcia et al. [25] who takes advantages of three Italian earthquakes as quasi-experiments and they studied the response of consumption to transfers to fund the housing reconstruction. It says that the transfers affect the liquidity of family wealth in the long term and it does not have effects on the consumption in the long term. However, there are some evident differences: increase non-sustainable consumption families that have low liquidity and bank debt. Meanwhile, those families which have liquidity do not show many differences.

Among all the researches that relate natural disasters to health, we should highlight that the ones that study personal mental health $[26,27]$. The incidence of post-traumatic stress resulting from the earthquake occurrence compared to a normal year has increased. It causes more damages to public health than traffic accidents, cardiovascular diseases or diabetes, which means it is needed to make psychosocial support plans for the affected communities [28]. Speaking of which, the research of Lopez [29] should be pointed out, who seeks to solve the questions such as to what extent financial services that have weakened consumption will increase the individual psychological strength when the natural disasters happen. The author studies the earthquake occurred in Chile in 2010. Among the results that the survey obtained, we should notice that to have earthquake insurance is related to the decrease of probability of having a disorder of post-traumatic stress that more than $50 \%$ of the people who live in properties that were damaged by the disaster have. In the same way, Palmeiro et al. [30] studied the same Chilean disaster and how does it affect the health of pregnant women's offspring. The authors find the relationship between the experience of stress caused by the disaster and the existence of earlier births and a reduction of the length and the circumference of the head of the newborn babies.

On the other hand, Adhikari et al. [31] study the effect of earthquakes in 2015 in Nepal, fuel crisis and power outages in Nepal's health services. From their results, it is pointed out that earthquakes generate short and long-term needs which differ from each other. Mean- while, power outages and fuel crises affect assistance. From the perspective of Epidemiology, there is literature that informs us of the outbreaks of infectious diseases following natural disasters. In this sense, [32] studies the earthquake in Nepal in 2015, where 360 samples were collected from the affected districts by the earthquake detecting Salmonella spp. and Shigella dysenteriae.

The economic problem faced by governments leads them to make decisions so difficult to allocate scarce resources, and among the priority areas health is one of the main responsibilities. Sen [33] points out that health is considered fundamentally in the field of social justice since it is one of the most important elements in our lives and also is valued by people. In this way, he considers an injustice as the fact that some cannot have the opportunity to achieve good health is because of a social issue and not because of a personal decision. For the same, health policies, in most countries, are based on the financial protection of people by reducing out-of-pocket spending for health, and this spending does not lead them to fall or remain in poverty [34].

The investments in health generate social and economic benefits and it should be high- lighted the direct relationship between health and economic growth, social welfare and the reduction of poverty [35]. It is reported that unhealthy state of adults can lead to the loss of family income due to absenteeism or low productivity of the individual [36]. In this context, governments carry out various public policies to guarantee that the health system works properly, highlighting the policies of the health systems (which are related to essential medicines, technology, and human resources, among others), primary care and the reforms in favor of universal coverage [37]. 
Table 1. Descriptive statistics

\begin{tabular}{cccccc}
\hline Variable & Observations & Mean & Standard Deviation & Minimum & Maximum \\
\hline Damage indicator & 53530 & 0.3298994 & 0.2447213 & 0 & 0.8412699 \\
Total of diseases & 53530 & 0.0423874 & 0.3607637 & 0 & 27 \\
Typhoid fever & 53530 & 0.0103493 & 0.1295412 & 0 & 10 \\
Paratyphoid fever & 53530 & 0.0014945 & 0.0436265 & 0 & 4 \\
Hepatitis A & 53530 & 0.0256305 & 0.2867299 & 0 & 27 \\
Salmonella & 53530 & 0.0049131 & 0.1644546 & 0 & 16 \\
\hline
\end{tabular}

\section{DATA}

This work uses different data sources. The first of them corresponds to the panel data of The National PostEarthquake Socioeconomic Characterization Survey that contains information at the household level, which was carried out months before and after the earthquake (CASEN 2010 post-earthquake), whose sample population is 75,986 people and 22,255 households respond in both years. The Ministry of Planning (MIDEPLAN) was in charge of conducting the Survey Post Earthquake, which currently corresponds to the Ministry of Social Development (MDS). Along with this database, it generates a housing damage indicator that takes values between 0 and 1.0 indicates that the house had no damage and 1 that it had some kind of damage. Subsequently, an average damage indicator of dwellings at the communal level that will be linked with the data that is pointed below.

Second, we used the data panel with foodborne diseases (ETA) between 2008 and 2013, constructed with the information of the number of mandatory notification diseases at the statistical week level, commune and type of disease, provided by the Ministry of Health. It was necessary to eliminate from the analysis the year 2010 because there is no continuous information available due to the disaster. The descriptive statistics of the diseases are shown in Table 1 and the number of total cases recorded in the study period for each type of studied disease (typhoid fever, paratyphoid fever, hepatitis A and salmonella) is presented in Table 2. The diseases of cholera, hepatitis $\mathrm{E}$ and $E$. coli were not considered because there are only a few cases in the study period, specifically 2, 16 and 13 cases, respectively.

The merging of the databases that we mentioned before allows us to respond to the set of research questions.

Table 2. Foodborne diseases (2008-2013)

\begin{tabular}{ccc}
\hline & Registered cases & \% \\
\hline Typhoid fever & 766 & 27.45 \\
Paratyphoid fever & 111 & 3.98 \\
Hepatitis A & 1645 & 58.94 \\
Salmonella & 269 & 9.64 \\
Total & 2791 & 100 \\
\hline
\end{tabular}

\section{METHODOLOGY}

The difference in Difference in Differences model, which is also known as the Triple Difference model, was used to study the effect of earthquakes on foodborne diseases. The use of this model requires that two assumptions should be met: The occurrence of the earthquake is an exogenous variation and that it is not related to other events that occur in the affected area. The occurrence of earthquakes cannot be predicted [38] according to the seismic history of our country [6] and the location of Chile over a zone of subduction of plates, which is known as the 'Pacific Ring of Fire' therefore, this first assumption is met. The second assumption that must be met is one of the parallel tendencies, that is to say, that there is no difference in the tendencies of the diseases between the affected areas and non-affected areas before the earthquakes happen. During the development of this work, we will focus on this assumption being met.

The first estimated model corresponds to a triple difference specification that seeks to end the effect of the disaster on the number of foodborne diseases, more explicitly:

$$
\begin{aligned}
y_{i t}=\beta_{i}+\beta_{i} \text { Aff } & \text { ected }_{i}+\beta_{2} \text { Post }_{t}+\beta_{3} \text { Trend } \\
& +\beta_{4} \text { Affected }_{i} \times \text { Post }_{t} \\
& +\beta_{5} \text { Affected } \\
& \times \text { Trend } \\
& +\beta_{6} \text { Post }_{i} \times \text { Trend } \\
& +\beta_{7} \text { Affected }_{i} \times \text { Post }_{t} \times \text { Trend } \\
& +\varepsilon_{i t}
\end{aligned}
$$

$y_{i t}$ is the dependent variable (number of diseases, worked as logarithm), $i$ corresponds to the commune and $t$ to the statistical week. Affected is a binary variable that indicates whether the commune was affected by the earthquake or not. Post corresponds to a binary variable that represents the period of time after the occurrence of the earthquake, and Trend represents the temporary trend for the unaffected area, represents the affected area in the subsequent period after the occurrence of the earthquake, represents the slope difference between the affected area and non-affected areas before the occurrence of the disaster, indicates the temporary trend for the non-affected region after the earthquake occurred, and represents the difference of slope between the affected area and non-affected zone after the occurrence of the disaster.

The results of the estimation allow us to see if the assumption of parallel tendencies is met, in another word, that there is no difference in the trends of diseases between the affected areas and non-affected areas before the earthquake. This allows us to determine if the estimated parameter is not significant which means there is no significant slope difference between the affected area and non-affected zones before the occurrence of the disaster. The effect of the earthquake in the area affected is captured by the estimated parameter, where we are interested in finding a significant difference between the slopes of the affected area and non-affected areas after the occurrence of the disaster, and that this difference is positive for the affected area The estimates including fixed effect by statistical week and commune, and with it, we managed to control all the differences that vary with time and all those that do not vary with time. We extend our results by type of disease.

The second estimated model aims to assess whether housing damage caused by the earth- quake affects the number of foodborne diseases. For this, we perform the following triple difference specification: 


$$
\begin{aligned}
y_{i t}=\beta_{i}+\beta_{i} \text { Damage }_{i}+\beta_{2} \text { Post }_{t}+\beta_{3} \text { Trend } & \\
& +\beta_{4} \text { Damage }_{i} \times \text { Post }_{t} \\
& +\beta_{5} \text { Damage }_{i} \times \text { Trend } \\
& +\beta_{6} \text { Post }_{i} \times \text { Trend } \\
& +\beta_{7} \text { Damage }_{i} \times \text { Post }_{t} \times \text { Trend } \\
& +\varepsilon_{i t}
\end{aligned}
$$

$y_{i t}$ is the number of diseases in the commune $i$ of the week $t$ and they worked as a logarithm. Damage is an indicator of the average damage of the houses in the commune $i$ as a consequence of the earthquake, and Post refers to periods of time following the occurrence of the earthquake. Therefore, $\beta_{5}$ indicates whether the assumption of parallel trends is met, and $\beta_{7}$ represents the impact of the damage of the houses in the number of diseases. We extend our results by type of disease.

From the previous model, it can be assumed that the variable damage presents an endogeneity, thinking that the most damaged houses belong to poorer people which are the lowquality constructions. To solve it we perform a minimum regression square in two stages (2SLS). First of all, we define our instrument that will be used. For that, we consider endogenous variable damage to the distance to the epicenter of the earthquake as an instrument since intuitively the most damaged houses are those that are located closer to the epicenter. After validating the instrument, we estimate the predicted value of the damage of the housing ceteris paribus, and then, in the second stage, we run the same regression and include the previous predicted value as a regressor.

Finally, we compare the estimated parameters of Affected and Damage, hoping to find a bigger magnitude in absolute value for those coefficients that accompany to the variable damage, assuming that housing damage is the direct mechanism of transmission of diseases and not the proximity to the epicenter of the earthquake.

\section{RESULTS}

In general, the results confirm the assumptions of the triple difference model (DDD). The areas affected and non-affected by the earthquake share the same tendencies before the disaster. In the time after the event, the affected area shows an increase compared to the non-affected area. The first estimated model (1) shows the effect of the earthquake in the total number of foodborne diseases before and after the earthquake. The results are in Table 3, where we can see in the first column that Trend (for the non-affected areas) is non-significant for the total of diseases, showing no tendency in the time previous the earthquake. The interaction between Trend $\times$ Affected is not significant (in the pre-treatment period), which indicates that there is no difference in the slopes of the affected and nonaffected areas, and thus the assumption of parallel trends is fulfilled. Finally, the triple interaction Post $\times$ Affect $\times$ Trend, shows that in the period after the earthquake the tendency of the diseases in the affected area increases in relation to the non-affected areas. When estimating the model (1) with the logarithm of the cases number for each type of disease, the results are different from the previously indicated. The results are in Table 3, shows that diseases typhoid fever, paratyphoid fever, and salmonella present the same temporal tendency in the period prior to the earthquake for the control and treatment groups, in other words, the assumption of parallel tendencies for the diseases mentioned above is con- firmed. In the postearthquake period, in the affected area, the diseases tendencies of salmonella and hepatitis A increases significantly compared to the control group. However, in the case of hepatitis A, despite the fact that there is evidence of an increase in the slope in the affected area in the period after the earthquake, both groups (control and treatment) do not share the same time trend in the period prior to the disaster. In the case of typhoid and paratyphoid fever, no subsequent effects after the earthquake are found.

It should be noted that after the catastrophe generated by the earthquake and the subsequent tsunami, the health system in conjunction with international help responded effectively two days after the disaster through an 'official list of requests for humanitarian aid' that allowed to receive donations from 31

\begin{tabular}{|c|c|c|c|c|c|}
\hline & $(\mathbf{1})$ & (2) & (3) & (4) & (5) \\
\hline Variable & Total & Typhoid & Paratyphoid & Hepatitis A & Salmonella \\
\hline \multirow{2}{*}{ Post } & $0.114 * * *$ & -0.00859 & -0.00407 & $0.0627 * * *$ & $0.0667 * * *$ \\
\hline & $(-0.0155)$ & $(-0.00669)$ & $(-0.00293)$ & $(-0.0112)$ & $(-0.00904)$ \\
\hline \multirow[t]{2}{*}{ Trend } & 0.00308 & $-0.00667 * *$ & -0.00155 & $0.0109 * * *$ & 0.000676 \\
\hline & $(-0.00448)$ & $(-0.00302)$ & $(-0.00144)$ & $(-0.00315)$ & $(-0.00116)$ \\
\hline \multirow[t]{2}{*}{ Affected } & -0.0208 & $-0.0165^{* *}$ & -0.00299 & $0.0360 * * *$ & $-0.0258 * *$ \\
\hline & $(-0.0139)$ & $(-0.00733)$ & $(-0.00244)$ & $(-0.0067)$ & $(-0.0112)$ \\
\hline \multirow[t]{2}{*}{ Trend*Post } & $-0.0202 * * *$ & 0.00468 & 0.00141 & $-0.0150 * * *$ & $-0.0118^{* * *}$ \\
\hline & $(-0.00517)$ & $(-0.00312)$ & $(-0.00147)$ & $(-0.0037)$ & $(-0.00196)$ \\
\hline \multirow[t]{2}{*}{ Trend*Affected } & -0.00522 & 0.00475 & 0.00124 & $-0.0112 * * *$ & -0.000575 \\
\hline & $(-0.00477)$ & $(-0.00322)$ & $(-0.0015)$ & $(-0.00333)$ & $(-0.00124)$ \\
\hline \multirow[t]{2}{*}{ Post*Affected } & $-0.131 * * *$ & 0.00703 & 0.00301 & $-0.0799 * * *$ & $-0.0651 * * *$ \\
\hline & $(-0.0165)$ & $(-0.00744)$ & $(-0.00311)$ & $(-0.012)$ & $(-0.0091)$ \\
\hline \multirow[t]{2}{*}{ Post*Affect*Trend } & $0.0259 * * *$ & -0.00334 & -0.00109 & $0.0200 * * *$ & $0.0113 * * *$ \\
\hline & $(-0.00551)$ & $(-0.00336)$ & $(-0.00154)$ & $(-0.00394)$ & $(-0.00201)$ \\
\hline \multirow[t]{2}{*}{ Constant } & 0.0182 & $0.0204 * * *$ & 0.00346 & $-0.0360 * * *$ & $0.0296 * * *$ \\
\hline & $(-0.014)$ & $(-0.00676)$ & $(-0.00232)$ & $(-0.00534)$ & $(-0.0113)$ \\
\hline Observations & 53530 & 53,530 & 53,530 & 53,530 & 53,530 \\
\hline R-squared & 0.143 & 0.037 & 0.01 & 0.133 & 0.123 \\
\hline Fixed eff. Commune & SI & SI & SI & SI & SI \\
\hline Fixed effect week & SI & SI & SI & SI & SI \\
\hline
\end{tabular}
countries. Among the most important donations received are the clinical furniture, medical and instrumental equipment, and medicines and supplies. This placed the health sector as one of the largest amounts of international donation perceived [39].

Table 3. Effect of the earthquake on the logarithm of diseases (2008-2013) 
Table 4. Effect of housing damage on the logarithm of total diseases (2008-2013)

\begin{tabular}{cccccc}
\hline & $\mathbf{( 1 )}$ & $\mathbf{( 2 )}$ & $\mathbf{( 3 )}$ & $\mathbf{( 4 )}$ & $\mathbf{( 5 )}$ \\
\hline Variable & Total & Typhoid Paratyphoid Hepatitis A & Salmonella \\
Post & $0.0995 * * *$ & -0.00269 & -0.00267 & $0.0612 * * *$ & $0.0460 * * *$ \\
& $(0.0116)$ & $(0.00522)$ & $(0.00220)$ & $(0.00858)$ & $(0.00634)$ \\
Trend & 0.00529 & -0.00229 & -0.000549 & $0.00792 * * *$ & 0.000510 \\
& $(0.00339)$ & $(0.00225)$ & $(0.00107)$ & $(0.00232)$ & $(0.00105)$ \\
Trend*Post & $-0.0203 * * * 0.000832$ & 0.000514 & $-0.0139 * * *-0.00836 * * *$ \\
& $(0.00391)$ & $(0.00235)$ & $(0.00109)$ & $(0.00277)$ & $(0.00151)$ \\
Trend*Damage & $-0.0186 * *$ & -0.00244 & -0.000199 & $-0.0165 * * *$ & -0.000809 \\
& $(0.00752)$ & $(0.00526)$ & $(0.00219)$ & $(0.00497)$ & $(0.00197)$ \\
Post*Damage & $-0.254 * * *$ & -0.00183 & 0.00262 & $-0.178^{* * *}$ & $-0.0858 * * *$ \\
& $(0.0268)$ & $(0.0140)$ & $(0.00522)$ & $(0.0198)$ & $(0.0123)$ \\
Post*Damage*Trend & $0.0593 * * *$ & 0.00407 & 0.000246 & $0.0422 * * *$ & $0.0154 * * *$ \\
& $(0.00883)$ & $(0.00565)$ & $(0.00229)$ & $(0.00620)$ & $(0.00289)$ \\
Constant & 0.0198 & $0.0127 * *$ & 0.00172 & $-0.0275 * * *$ & $0.0324 * * *$ \\
& $(0.0133)$ & $(0.00591)$ & $(0.00172)$ & $(0.00429)$ & $(0.0113)$ \\
Observations & 53,530 & 53,530 & 53,530 & 53,530 & 53,530 \\
R-squared & 0.143 & 0.037 & 0.010 & 0.133 & 0.121 \\
Fixed eff. Commune & SI & SI & SI & SI & SI \\
Fixed effect week & SI & SI & SI & SI & SI \\
\hline \multicolumn{5}{c}{ Robust standard errors in parentheses: *** p<0.01, ** p<0.05, * p<0.1 }
\end{tabular}

Table 5. Effect of housing damage on the logarithm of total diseases (2SLS) (2008-2013)

\begin{tabular}{cccccc}
\hline & $\mathbf{( 1 )}$ & $\mathbf{( 2 )}$ & $\mathbf{( 3 )}$ & $\mathbf{( 4 )}$ & $\mathbf{( 5 )}$ \\
\hline Variable & Total & Typhoid & Paratyphoid Hepatitis A Salmonella \\
Post & $0.224^{* * *}$ & $-0.0180^{*}$ & -0.00348 & $0.131 * * *$ & $0.119^{* * *}$ \\
& $(-0.0272)$ & $(-0.0102)$ & $(-0.00377)$ & $(-0.0204)$ & $(-0.0168)$ \\
Trend & 0.00217 & $-0.00928^{*}$ & -0.00113 & $0.0125 * * *$ & 0.000552 \\
& $(-0.00679)$ & $(-0.00481)$ & $(-0.00179)$ & $(-0.0048)$ & $(-0.00217)$ \\
Trend*Post & $-0.0358^{* * *}$ & 0.00736 & 0.000857 & $-0.0247 * * *-0.0205 * * *$ \\
& $(-0.00821)$ & $(-0.00493)$ & $(-0.00184)$ & $(-0.00599$ & $(-0.00364)$ \\
Trend*Damage & -0.00915 & 0.0187 & 0.00156 & $-0.0305 * *$ & -0.000937 \\
& $(-0.0179)$ & $(-0.0128)$ & $(-0.00448)$ & $(-0.0126)$ & $(-0.00575)$ \\
Post*Damage & $-0.630^{* * *}$ & 0.0445 & 0.00507 & $-0.389 * * *$ & $-0.306 * * *$ \\
& $(-0.0726)$ & $(-0.0276)$ & $(-0.00975)$ & $(-0.0546)$ & $(-0.0443)$ \\
Post*Damage*Trend & $0.106 * * *$ & -0.0157 & -0.000792 & $0.0749 * * *$ & $0.0522 * * *$ \\
& $(-0.0217)$ & $(-0.0131)$ & $(-0.00463)$ & $(-0.0159)$ & $(-0.00962)$ \\
Constant & 0.00377 & $0.0270 * * *$ & 0.00322 & $-0.0528 * * *$ & $0.0253 * *$ \\
& $(-0.016)$ & $(-0.00902)$ & $(-0.00279)$ & $(-0.00777)$ & $(-0.0116)$ \\
Observations & 53,530 & 53,530 & 53,530 & 53,530 & 53,530 \\
R-squared & 0.132 & 0.035 & 0.01 & 0.123 & 0.102 \\
Fixed eff. Commune & SI & SI & SI & SI & SI \\
Fixed effect week & SI & SI & SI & SI & SI \\
\hline \multicolumn{5}{c}{ Robust standard errors in parentheses: *** p<0.01, ** p<0.05, * p<0.1 }
\end{tabular}

Despite this intervention, we can see a correlation between the occurrence of the earthquake and the increase in foodborne diseases in the affected area after the disaster. This suggests working preventatively on issues related to health education post-disaster, and in an active way to focus the necessary assistance to the affected households.

Previous estimates show a correlation between the occurrence of the disaster and the increase of the number of foodborne diseases in the area affected by the earthquake. However, we want to study if housing damage is the direct transmission mechanism. For this, we estimate the (2) model and the results obtained are shown in Table 4. We can see in column (1) that the trend coefficient is not significant for the total of diseases, reflecting no trend in the period prior to the earthquake, and for the areas where the houses were not damaged. Then, the interaction between Trend $\times$ Damage is significant at $5 \%$ significance in the pre-treatment period, indicating that between areas with greater and lesser damage the tendency of the total of diseases differs, therefore the assumption of parallel tendencies is not fulfilled. In the triple interaction Post $\times$ Damage $\times$ Trend, you can see that diseases tendency increases in areas with damaged homes in the period after the earthquake, which indicates a correlation between housing damage and increase of disease.

Regarding the impact of housing damage on the disease by type, the results in columns (2), (3), (4) and (5) show that the parallel tendency assumption is correct for the period prior to the earthquake for typhoid, paratyphoid, and salmonella. After the earthquake the triple interaction Post $\times$ Damage $\times$ Trend shows that in areas with damaged houses the trend increases for all disease compared to those without damaged houses, specifically typhoid fever increases by $0.4 \%$, paratyphoid fever $0.02 \%$, hepatitis A $4.2 \%$ and salmonella $1.5 \%$, this increase is significant at $1 \%$ for the last two. These results confirm our working hypothesis, that the areas where the houses present the most damage correlates with a greater number of foodborne diseases due to the deterioration or destruction of the house, the lack of water, electricity or sewerage, among others.

We perform a two-stage least squares (2SLS) regression and we use as an instrument for the endogenous variable Damage 
to Distance to the epicenter of the earthquake, since intuitively the most damaged homes are those located closest to the epicenter. The Distance variable turns out to be statistically significant at $1 \%$, which indicates that it is a good instrument. Then we calculate the predicted value of the model and include it in the estimation of the structural equation. The results obtained in the second stage are shown in Table 5. In the chart we can see that the tendency coefficient is not significant at $5 \%$ for the total of disease and for the cases of typhoid, paratyphoid, and salmonella, reflecting no tendency in the period prior to the earthquake.

We can see that the coefficient of the interaction between Trend $\times$ Damage is not significant, for the total of diseases and for the cases of typhoid, paratyphoid and salmonella, which indicates that in the period prior to the earthquake the zones whose houses were damaged and the zones whose houses were not damaged, fulfill the assumption of parallel tendencies. Then, the triple interaction Post $\times$ Damage $\times$ Trend shows that, after the earthquake, the trend in areas with damaged homes increases by $10.6 \%$ for total diseases, increases by $7.5 \%$ for hepatitis A and $5.2 \%$ for salmonella, compared to the undamaged areas. In the particular case of hepatitis A, despite not meeting the assumption of parallel tendency in the period prior to the earthquake, in the period after it decreases the trend for undamaged housing areas and increases in areas whose homes are damaged.

\section{CONCLUSIONS}

Natural disasters such as earthquakes generate significant economic costs, which are associated with the destruction of houses and sanitary infrastructure in houses. In this sense, the purpose of this work is to study how the occurrence of the earthquake is related to the increase of foodborne diseases and the study considers that the lack of drinking water, sanitation and hygiene are an important cause of contagion. We focus on the earthquake happened in Chile, 2010, and we use microlevel data from a household survey carried out three months after the disaster, together with the data provided by the Ministry of Health of diseases of food transmission.

The results illustrate that after the earthquake, the area affected by the disaster shows a significant increase of $2.6 \%$ of the total number of diseases compared to the non-affected areas. When estimating the model by type of disease, the results differ from those indicated above. In the period after the earthquake, in the affected region, the increase of the percentage of hepatitis $\mathrm{A}$ is $2 \%$ and of salmonella is $1.1 \%$, respectively; however, the parallel trends only work for the case of salmonella.

When correlating the housing damage with the diseases, the results show that in the areas where the houses were damaged by the earthquake, the cases of total diseases increase by $5.9 \%$ compared to the non-damaged dwellings. When estimating the model by type of disease, we found that all of them correlate positively with housing damage in the post-earthquake period. This increase is significant for cases of hepatitis A and salmonella. The only type of disease that does not meet the assumption of parallel trends is hepatitis A. By performing a least-squares regression in two stages and using the Distance instrument for the Damage variable, the results reinforce those already obtained, specifically in the post-earthquake period the total of diseases increases by $10.6 \%$, hepatitis A in $7.5 \%$ and salmonella in $5.2 \%$. The results conform to our hypothesis because we find a causal relationship between the occurrence of an earthquake and the incidence of foodborne diseases, but undoubtedly, the damage of dwellings is related to the increase of foodborne diseases. The total number of diseases increases significantly in the post-earthquake period, as well as hepatitis A and salmonella, and the estimated parameters increase in magnitude while we make the estimation more precise and solve the endogeneity problems.

To conclude, this work constitutes a source of evidence for the intervention and generation of public policies in the field of health. As future work, it is recommended to study the rate at which each disease returns to a steady state, that is, to determine the time it takes to return to the tendency of the zone before the disaster. In the same way, we study the relationship that exists between the occurrence of other types of disasters and the incidence of possible associated diseases.

\section{REFERENCES}

[1] Bitar, S. (2010). Doce lecciones del terremoto chileno. Estado, Gobierno, Gestión Pública: Revista Chilena de Administración $\quad$ Pública, $\quad$ (15): 7-18. https://doi.org/10.5354/0717-6759.2010.11205

[2] Razeto Pavez, A.C. (2013). Potenciando el desarrollo local de comunidades afectadas por desastres. Revista INVI, 28(77): 111-136. https://doi.org/10.4067/s071883582013000100004

[3] Perez, E., Thompson, P. (1994). Natural hazards: Causes and effects: Lesson 2-earthquakes. Prehospital and Disaster Medicine, 9(4): 260-272. https://doi.org/10.1017/s1049023x00041510

[4] Naghii, M.R. (2005). Public health impact and medical consequences of earthquakes. Revista Panamericana de Salud Pública, 18(3): 216-221. https://doi.org/10.1590/s1020-49892005000800013

[5] Alvarez, G., Ramirez, J., Paredes, L., Canales, M. (2010). Zonas oscuras en el sistema de alarma de advertencia de tsunami en Chile. Ingeniare. Revista Chilena de Ingeniería, $18(3)$ : 316-325. https://doi.org/10.4067/s0718-33052010000300005

[6] Lara, H.P., Trujillo, C.H. (2010). Los terremotos: una amenaza natural latente. Scientia et Technica, 2(45): 303308. http://dx.doi.org/10.22517/23447214.341

[7] Samaniego, J. (2010). Terremoto en Chile: una primera mirada al 10 de marzo de 2010.

[8] Figueroa, R.A., González, M., Torres, R. (2010). Plan de reconstrucción psicológica post terremoto. Revista médica de Chile, 138(7): 920-921. https://doi.org/10.4067/s0034-98872010000700020

[9] World Health Organization. (2007). Lucha contra las enfermedades transmitidas por el agua en los hogares.

[10] World Health Organization. (2015). Who estimates of the global burden of foodborne diseases: Foodborne disease burden epidemiology reference group 2007-2015.

[11] Boschi-Pinto, C., Velebit, L., Shibuya, K. (2008). Estimating child mortality due to diarrhoea in developing countries. Bulletin of the World Health Organization, 86(9): 710-717. https://doi.org/10.2471/blt.07.050054

[12] Ratnaike, R.N. (1999). Diarrhoea and aging. Journal of Postgraduate Medicine, 45(2): 60.

[13] EFSA. (2010). The community summary report: Trends and sources of zoonoses and zoonotic agents and foodborne outbreaks in the European Union in 2008. European 
Food Safety Authority.

[14] Blaikie, P.M. (1996). Vulnerabilidad: el entorno social, político y económico de los desastres. Soluciones Prácticas.

[15] Blaikie, P., Canon, T., Davis, I., Wisner, B. (2014). At Risk: Natural Hazards, People's Vulnerability and Disasters. Routledge.

[16] Guha-Sapir, D., Vos, F., Below, R., Ponserre, S. (2012). Annual Disaster Statistical Review 2011: The Numbers and Trends. Centre for Research on the Epidemiology of Disasters (CRED)

[17] Mechler, R. (2004). Natural Disaster Risk Management and Financing Disaster Losses in Developing Countries.

[18] Lavell, A. (1994). Viviendo en riesgo: Comunidades vulnerables y prevención de desastres en América Latina. La Red.

[19] Pelling, M., Özerdem, A., Barakat, S. (2002). The macroeconomic impact of disasters. Progress in Development Studies, 2(4): 83-305. https://doi.org/10.1191/1464993402ps042ra

[20] Cavallo, E., Noy, I. (2010). The aftermath of natural disasters: Beyond destruction. In CESifo Forum, München: ifo Institut für Wirtschaftsforschung an der Universität München, 11: 25-35.

[21] PNUD \& BCPR. (2004). La reducción de riesgos de desastres un desafío para el desarrollo. Informe mundial.

[22] UNISDR, C. (2015). The Human Cost of Natural Disasters: A Global Perspective.

[23] Anderson, M.B. (1991). Which costs more: prevention or recovery. Managing Natural Disasters and the Environment. Washington, DC: World Bank.

[24] Kahneman, D., Krueger, A.B. (2006). Developments in the measurement of subjective well-being. Journal of Economic Perspectives, 20(1): 3-24. https://doi.org/10.1257/089533006776526030

[25] Acconcia, A., Corsetti, G., Simonelli, S. (2015). The consumption response to liquidity- enhancing transfers: Evidence from Italian earthquakes. Institute for New Economic Thinking, Working Paper Series No: 2015/10.

[26] Schwandt, H. (2018). Wealth shocks and health outcomes: Evidence from stock market fluctuations. American Economic Journal: Applied Economics, 10(4): 349-377. https://doi.org/10.1257/app.20140499

[27] Engelberg, J., Parsons, C.A. (2016). Worrying about the stock market: Evidence from hospital admissions. The Journal of Finance, 71(3): 1227-1250. https://doi.org/10.1111/jofi.12386

[28] Figueroa, R.A., González, M., Torres, R. (2010). Plan de reconstrucción psicológica post terremoto. Revista Médica de Chile, 138(7): 920-921. https://doi.org/10.4067/s0034-98872010000700020

[29] Lopez, F. (2015). How do financial services affect investor psychology? Available at SSRN 2318912.

[30] Palmeiro-Silva, Y.K., Orellana, P., Venegas, P., Monteiro, L., Varas-Godoy, M., Norwitz, E., Rice, G., Osorio, E., Illanes, S.E. (2018). Effects of earthquake on perinatal outcomes: A Chilean register-based study. PloS One, 13(2): e0191340. https://doi.org/10.1371/journal.pone.0191340

[31] Adhikari, B., Mishra, S.R., Marahatta, S.B., Kaehler, N., Paudel, K., Adhikari, J., Raut, S. (2017). Earthquakes, fuel crisis, power outages, and health Care in Nepal: Implications for the future. Disaster Medicine and Public Health Preparedness, 11(5): 625-632. https://doi.org/10.1017/dmp.2016.195

[32] Shakya, G., Marasini, B., Karki, K., Upadhaya, B., Acharya, J., Adhikari, S., Manjhi, R., Maharjan, L., Shrestha, L., Ranabhat, K., Marahatta, S., Shrestha, B., Dhimal, M. (2018). Outbreak investigation following the 2015 earthquake disaster in Nepal. Journal of Nepal Health Research Council, $\quad$ 16(1): 61-65. https://doi.org/10.3126/jnhrc.v16i1.19368

[33] Sen, A. (2002). Por qué la equidad en salud? Revista Panamericana de Salud Pública, 11(1-5): 302-309. https://doi.org/10.1590/s1020-49892002000500005

[34] Organización Mundial de la Salud. Informe sobre la salud en el mundo: la financiación de los sistemas de salud: el cambio hacia la cobertura universal. Organización Mundial de la Salud. 2010.

[35] Pick, S., Sirkin, J. (2011). Pobreza: Cómo romper el ciclo a partir del desarrollo humano, Limusa.

[36] Yamey, G., Beyeler, N., Wadge, H., Jamison, D. (2017). Invirtiendo en salud: el argumento económico. Informe del Foro sobre Inversión en Salud de la Cumbre Mundial sobre Innovación para la Salud 2016. Salud Pública de México, 59(3): 321-342. https://doi.org/10.21149/8675

[37] Chan, M. (2009). La atención primaria de salud, más necesaria que nunca.

[38] Lagos, M.L., Cisternas, M.C. (2008). El nuevo riesgo de tsunami: considerando el peor escenario. Scripta Nova: revista electrónica de geografía y ciencias sociales, 25(12).

[39] López Tagle, E., Santana Nazarit, P. (2011). El terremoto de 2010 en Chile: respuesta del sistema de salud y de la cooperación internacional. Revista Panamericana de Salud Pública, 30: 160-166. 